\title{
Improving the Degree of Autarky of a 16 House Neighbourhood in the Netherlands - A case study
}

\author{
Stefano Nebiolo, Bart Homan, Gerwin Hoogsteen, Johann L. Hurink, Gerard J.M. Smit \\ Department of EEMCS, University of Twente, Enschede, the Netherlands \\ Corresponding authors: b.homan@utwente.nl,g.hoogsteen@utwente.nl
}

\begin{abstract}
In this work we investigate the practical applicability of "soft-islanding" (near autarkic behaviour) of an existing neighbourhood with 16 houses in the Netherlands. In order to achieve this, a multi-energy system, including optimal control, is modeled using PV panels, a combined heat and power generator and $6 \mathrm{kWh}$ of battery storage per household. By utilizing the synergies between electricity, heat and bio-gas, the system is a good solution to relieve stress on electricity grids within the context of the energy transition. Simulation studies show that the envisioned system, with control, is able to reach a Degree of Autarky of $91 \%$.

Index Terms-Micro-grids, energy management, optimization, multi-energy systems
\end{abstract}

\section{INTRODUCTION}

With a drastic, country-wide reduction in the emission of $\mathrm{CO}_{2}$ as the main goal, the Energy Transition is an ongoing effort to structurally change the energy usage in the Netherlands [1]. Dominant in this transition is to reduce the dependence on natural gas, which is the primary energy source for space heating and cooking in the Netherlands [2]. However, simply switching to all-electric cooking and heating is not feasible as the electrical grid in the Netherlands is not designed for such loads [3] and existing insulation may not be suitable.

A possible solution to this problem is to reduce the potential strain on the electricity infrastructure by matching local generation and demand using intelligent control and optimization, such as presented in e.g. [4]. To completely avoid stress on the electricity grid, a group of households can be disconnected from the grid [5] i.e. in an islanded micro-grid. However, creating such an islanded micro-grid can be expensive and is often not strictly required as energy infrastructure is already available. Instead, a group of households can operate softislanded, meaning that there is still a connection to the main grid for stabilization, but the majority of energy is shared locally. The objective of such a soft-islanded grid is to maximize the Degree of Autarky (DoA) which expresses the share of locally produced and used (without transport) energy. A definition of the DoA is presented in Section IV.

Such a soft-islanded microgrid is not limited to the control of electricity, however. Synergies between multiple energy carriers, such as electricity and heat, can be utilized to improve the overall system efficiency. Mancarello [6] has surveyed concepts and models for such integrated multi-energy systems (MES). It has to be noted that the configuration heavily depends on the local conditions and climate, see e.g. [7], [8].
For the Netherlands, given the climate conditions with mild winters, combining PV with a Combined Heat and Power (CHP) unit proves to be a complementary mix to generate enough electricity throughout the year for such soft-islanded operation. In previous work, [9], we demonstrated that it is possible to drastically reduce the electricity imports from the grid with such a system, combined with small scale storage and optimal control.

This paper presents a feasibility study to soft-island an existing neighbourhood, consisting of 16 houses, in the Dutch town Markluiden with the aforementioned system design as presented in [9]. The fuel of the CHP is considered to be bio-gas, which can be produced from sources in the direct vicinity of the town. The simulation studies are carried out using the DEMKit software [10] developed at the University of Twente. This tool allows us to model such a MES on the level of individual devices. Furthermore, different optimization algorithms are implemented in DEMKit to perform the softislaning study. More specifically, we use Profile Steering [11] as optimization framework, coupled with a double-sided auction for operational control [12].

Characteristics of this neighbourhood, together with reasons why this location is potentially suitable for soft-islanding are discussed in Section II. The process to size the various components within the hybrid-energy system to perform softislanding is presented in Section III. The sizing is followed by results of a simulation study of a complete year, using optimal control, to obtain the DoA that can be expected in Section IV. Lastly, our conclusions are presented in Section V. Additional details on Markluiden and an expanded case study are presented in [13].

\section{CHARACTERISTICS OF THE NEIGHBOURHOOD}

In Figure 1 a layout of the neighbourhood is given. The neighbourhood consists 16 unique and fully detached houses, The residents are open to share data about their energy usage and schedules, and are willing to share their locally generated energy with their neighbours. Moreover, the residents filled out questionnaires to provide us with the information required for this case study.

Most of the houses were built several decades ago, with little to moderate insulation. There are a couple of exceptions, two houses were built recently, which are very well insulated. Furthermore, only one of the houses makes use of renewable energy technology; it is outfitted with $12 \mathrm{PV}$-panels and 2 


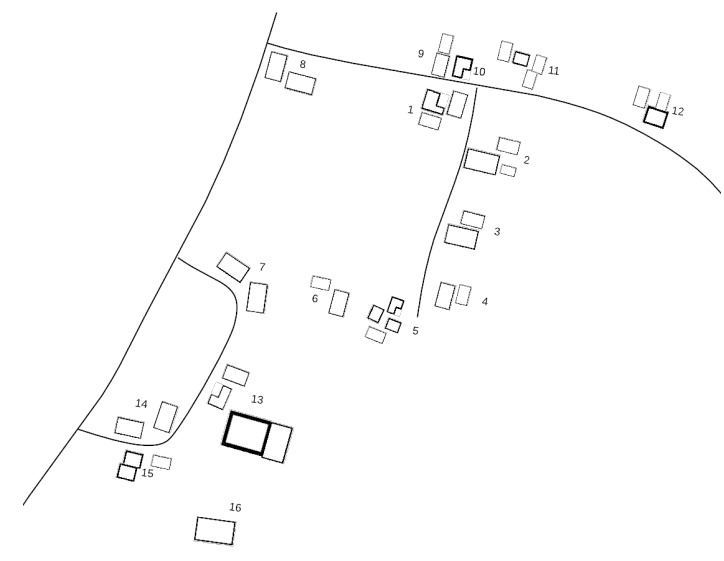

Fig. 1. Layout of the 16 house neighbourhood in Markluiden.

PVT-panels. In total 11 of the 16 houses are suitable for the installation of PV-panels. The remaining houses have a thatched roof, (i.e. made of straw) which makes installation of PV-panels impossible. For these houses PV-panels will be installed elsewhere on the property (i.e on the roof of a shed or annex).

In most of the houses, the heat is generated by a traditional high-efficiency gas boiler and delivered to the indoor area using high-temperature radiators. Additionally, in 7 of the houses floor heating is used. In only one of the houses floor heating is used as the only means of heating.

The orientation of the houses is mixed, with seven houses East-West oriented and the remaining nine South-North oriented. The window area was defined by use of standardized values depending on the year of construction and type of house [14]. The total area was then divided over all sides of the building after analysing the household location and geometry by use of an online map. On average the houses have a window area of $31 \mathrm{~m}^{2}$, divided in $4.5 \mathrm{~m}^{2}$ facing north, $8 \mathrm{~m}^{2}$ facing west, $7.8 \mathrm{~m}^{2}$ facing east and $10.6 \mathrm{~m}^{2}$ facing south.

Lastly, the availability of underground water deposits make the Markluiden neighbourhood suitable for the usage of an aquifer thermal energy storage (ATES) system. This system provides inter-seasonal heat storage, which is useful for the poor insulation of the households in this case. The use of ATES also makes it possible to skip the sizing of a thermal buffer as considered in [9].

\section{SIZING THE EQUIPMENT}

In this section the proper size of this equipment is determined. The details of the town and results of the questionnaires are used as input for the Artificial Load Profile Generator [15]. This results in a solid basis, including time series power consumption profiles, to model the current state of the neighbourhood. From this basis, we add the technologies to enable soft-islanding to this model and size them accordingly. A primary constraint here is that the comfort of connected customers may not be violated, e.g. they need to be supplied with the heat and electricity they demand. This sizing process is executed in three steps:

- Firstly, we size the CHP to fulfill the heat and electricity demand during the colder months in our dataset (note that the usage of ATES allows us to neglect the sizing of buffer storage).

- Secondly, the number of PV panels is determined to ensure that enough energy is generated during the longer and sunnier months.

- Thirdly, the battery storage is sized to to match supply and demand throughout the day by shifting energy in time, e.g. electricity produced by PV to the evening.

For the sizing, a set of three weeks with varying properties is used. Week A in the summer, week B in the winter and week $\mathrm{C}$ in the autumn, of which the details given in Table I. The weather data used in this work was obtained from [16]. The control actions of the added technologies are optimized using the Profile Steering algorithm [11] and simulated using DEMKit [10].

TABLE I

DESCRIPTION OF THE TEST WEEKS.

\begin{tabular}{l|lll}
\hline Week & Date & PV generation & Heat demand \\
\hline A & 30 Jul. - 5 Aug. & very high & very low \\
B & 22 - 28 Jan. & low & very high \\
C & $15-21$ Oct. & low & low \\
\hline
\end{tabular}

\section{A. The CHP unit}

As the comfort of the residents is the most important constraint, the CHP unit capacity must be large enough to satisfy the heat demands of all houses in the coldest week of the year (i.e. week B) ${ }^{1}$. The setpoint selected to trigger the heating device during the day is $18.0^{\circ} \mathrm{C}$. Furthermore, the minimum allowed temperature in the house during night hours (between 23:00 and 8:00) is $14.0^{\circ} \mathrm{C}$. In Figure 2, the average zone temperature in week B for different CHP unit capacities (from $100 \mathrm{~kW}_{\text {th }}$ to $250 \mathrm{~kW}_{\text {th }}$ ) is given.

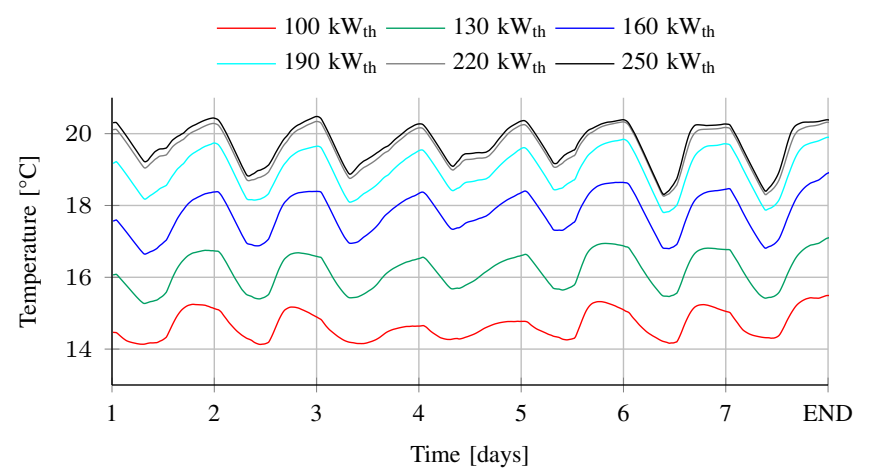

Fig. 2. Zone temperature for varied CHP sizes.

\footnotetext{
${ }^{1}$ Note that it would also be prudent to improve the thermal insulation wherever possible, however, this has not been taken into account in this study.
} 
From Figure 2 it is clear that CHP units with capacities from $190 \mathrm{~kW}_{\text {th }}$ upwards can guarantee the thermal comfort inside the houses on average. However, investigation of individual temperature profiles of each household shows that a CHP capacity of $190 \mathrm{~kW}_{\text {th }}$ does not guarantee thermal comfort to some houses.A CHP unit with $250 \mathrm{~kW}_{\text {th }}$ power output is the minimum capacity that can ensure thermal comfort in all the houses of the micro-grid, and hence this size is selected

Electricity is produced by the CHP as a by-product from the heat-generation. The rest of the electricity demand should be met by the PV-panels and by using the batteries optimally. The CHP used in the Markluiden micro-grid has a heat / electricity production ratio of 2.25 . As mentioned in Section II, the Markluiden neighbourhood is particularly suitable for an ATES system for the storage of thermal energy. The selected ATES system has a thermal capacity of $5 \mathrm{MWh}_{\text {th }}$.

\section{B. The PV panels}

The sizing of the PV panel area is done using an analysis of week $A$. This is the warmest week in which the CHP will produce the least electricity and thus the micro-grid depends on the production from on the PV panels. For the determination PV-panels of 19\% efficiency are considered, as these are already used in the neighbourhood. Furthermore, the PV-panels are assumed to be installed facing south wherever possible, and equally divided towards east and west in all other cases. The the total surface of PV panels per household is varied from $8 \mathrm{~m}^{2}$ to $24 \mathrm{~m}^{2}$. Lastly, in this determination a $13,5 \mathrm{kWh}$ battery per household is used to avoid capacity limitations in shifting energy from day to night. Note that the battery size itself will be optimized in the next subsection, where trade-offs between autarky and costs can be made.

Figure 3a shows the electricity usage of the micro-grid given the different PV panels area, while Figure $3 b$ shows the SoC of the battery. From Figure $3 \mathrm{a}$ it is clear that even for the highest PV installation $\left(24 \mathrm{~m}^{2}\right)$, electricity is still imported from the grid, mostly at night. Figure 5a gives the amounts of electricity imported from the grid depending on the PV-panel areas, from which it is clear that the benefits beyond $16 \mathrm{~m}^{2}$ of PV panels per household is very limited. Hence, again taking into account the cost of a $\mathrm{m}^{2} \mathrm{PV}$-panel, a PV-panel area of 16 $\mathrm{m}^{2}$ per house is selected.

\section{The batteries}

The sizing of the capacity of the electrical storage is done using an analysis of week $A$. For this analysis battery capacities of 3, 4, 5, 6, 7, 9, 11 and $13,5^{2} \mathrm{kWh}$ are considered. Figure 4 , the electricity usage of the micro-grid and the stateof-charge (SoC) of the batteries are shown.

From Figure $4 \mathrm{a}$, it is clear that the total imports from the grid decrease when the battery capacity is increased. Figure $5 \mathrm{~b}$ shows the amount of electricity imports during week A given the different battery sizes. With a total battery capacity of $3 \mathrm{kWh}$ per household ( $48 \mathrm{kWh}$ in total), almost $135 \mathrm{kWh}$

\footnotetext{
${ }^{2} 13,5 \mathrm{kWh}$ corresponds to a Tesla Powerwall 2 battery, this specific battery is taken into account on the request of the Markluiden residents.
}

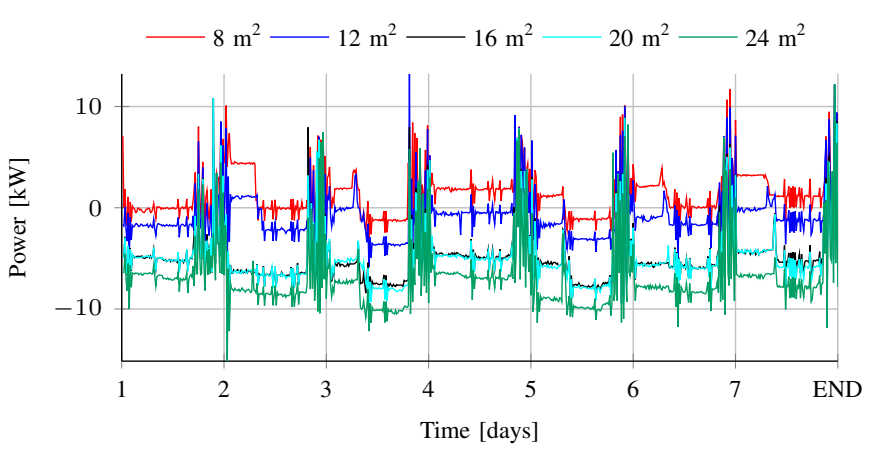

(a) Electricity usage.

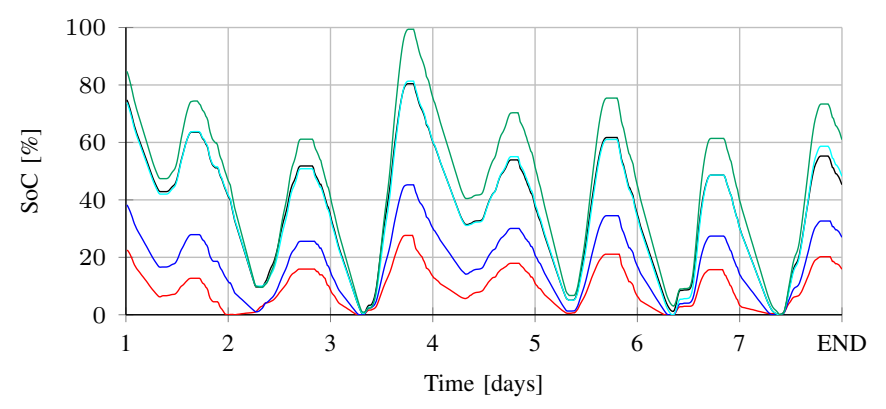

(b) SoC batteries.

Fig. 3. Electricity usage and $\mathrm{SoC}$ of batteries for varied PV-panel areas

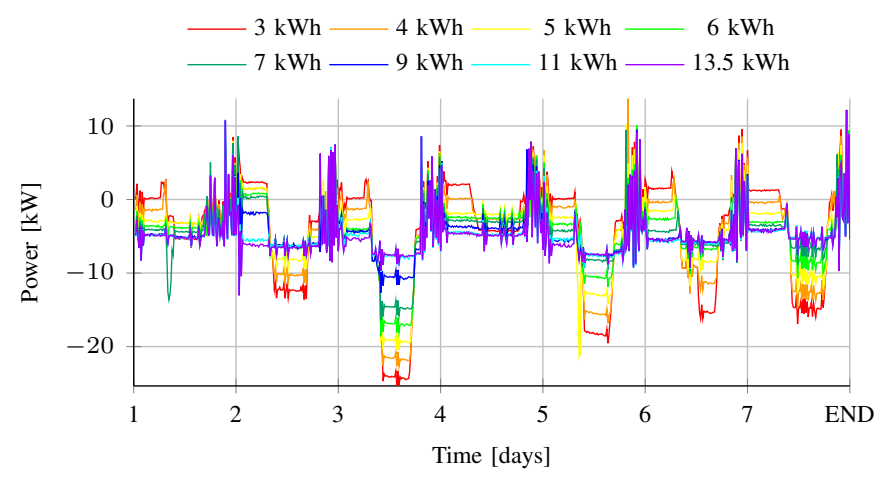

(a) Electricity usage

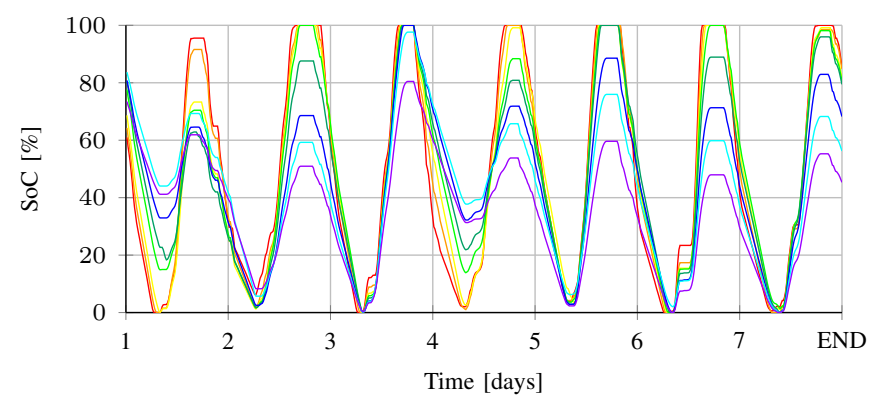

(b) SoC batteries.

Fig. 4. Electricity usage and SoC of different battery sizes 
of electricity is still imported from the grid. By increasing the battery capacity to $6 \mathrm{kWh}$ per householf the import is reduced. However, beyond this $6 \mathrm{kWh}$ per household, the improvement is little. Moreover, we observe that the full capacity of a battery of more than $6 \mathrm{kWh}$ is never fully utilised, i.e. the SoC never reaches $100 \%$ (see Figure $4 b$ ). So increasing the battery capacity any further would not yield improvements and thus a battery of $6 \mathrm{kWh}$ per household is selected.

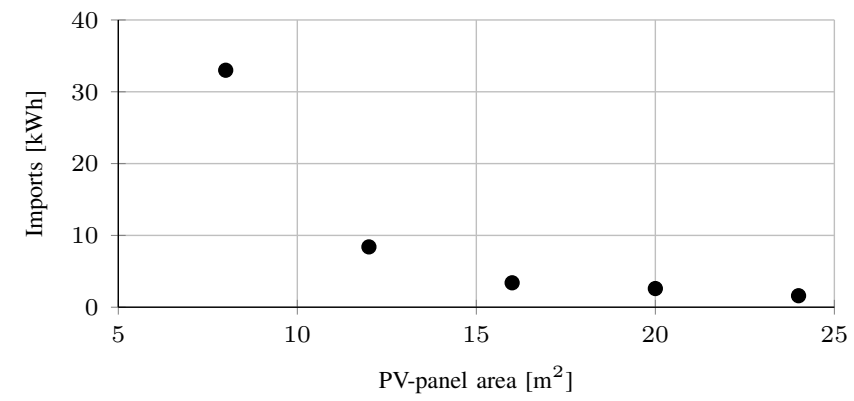

(a) PV-panel area

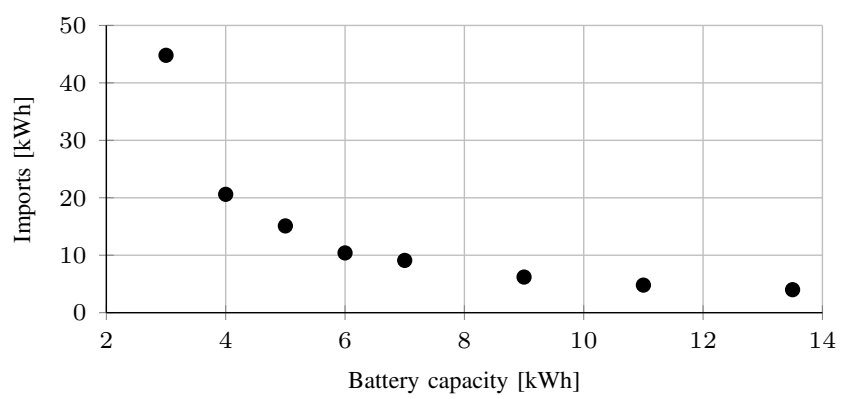

(b) Battery capacity

Fig. 5. Necessary electricity imports for the considered battery capacities and PV-panel areas.

\section{RESULTS}

One year of the Markluiden soft-islanded microgrid, with the technologies as sized in Section III (see Table II, is modeled and simulated using the DEMKit simulator [10] to evaluate its potential in two specific cases. The first case is the NC case, in which no control and optimization is applied, nor batteries are used. Optimization of storage and CHP operation is considered in the PS case. In this case, we use Profile Steering [11] with the objective to minimize the quadratic deviation from power balance $(0 \mathrm{~W})$. Herein, Profile Steering uses a model predictive control method to optimize the energy profile for the upcoming two days using a rolling horizon

TABLE II

SUMMARY OF EQUIPMENT SIZING.

\begin{tabular}{l|l}
\hline Equipment & Size \& configuration \\
\hline CHP unit & $250 \mathrm{~kW}_{\text {th }} / 111 \mathrm{~kW}_{\mathrm{el}}$ \\
CHP buffer & $5 \mathrm{MWh}$ (ATES) \\
Battery & $6 \mathrm{kWh} /$ house \\
PV-panels & $16 \mathrm{~m}^{2} /$ house (19\% eff.) \\
\hline
\end{tabular}

approach. Furthermore, to resolve prediction errors, a doublesided auction [12] is used for operational control (see also [10]). The two different cases are then compared with the present situation in Markluiden, the $\mathbf{R}$ (reference) case.

For the islanding of the energy system, all the energy consumed within the system must be locally produced. This aspect can be quantified with the Degree of Autarky (DoA), which is the percentage of energy consumption ( $\left.E_{\text {consumption }}\right)$ from local sources, i.e.

$$
\mathrm{DoA}=\frac{E_{\text {consumption }}-E_{\text {import }}}{E_{\text {consumption }}} \times 100 \%,
$$

where $E_{\text {import }}$ is the total amount of imported energy.

In the $\mathrm{R}$ case, almost the entire electricity load comes from the grid. Only a little percentage of the total electricity demand of the 16 houses comes from the PV panels installed on the rooftop of one house. Consequently, the energy system is far from islanding, with a resulting DoA of only $3.7 \%$.

In the $\mathrm{NC}$ case, the yearly average electricity consumption per house is 3.7 MWh while the average electricity production per house is $16 \mathrm{MWh}$ (see Table III). The average heat demand per house is $19.6 \mathrm{MWh}_{\text {th }}$, which is completely satisfied by the heat produced by the CHP. The majority of the electricity (12.2 MWh per house) is generated by the CHP as a byproduct of the heat generation, however, only 2.0 MWh of this is used locally. The PV panels generate $3.8 \mathrm{MWh}$ per house over the year but only $830 \mathrm{kWh}$ is consumed locally. The excess electricity produced by the CHP and PV-panels, 13.1 MWh per house for the entire year is exported to the grid, while $840 \mathrm{kWh}$ is still imported. This yields a DoA of $77.3 \%$ i.e. just over three quarters of the electricity load of the neighbourhood does not burden the grid. This is a remarkable improvement compared to the $\mathrm{R}$ case. However, this is still far from soft-islanding this neighbourhood.

TABLE III

STATISTICS OF THE ANNUAL HOUSEHOLD ELECTRICITY USAGE.

\begin{tabular}{rccccccc}
\hline & {$[\mathbf{k W h}]$} & {$[\mathbf{k W h}]$} & {$[\%]$} & \multicolumn{4}{c}{ Share in electricity supply [\%] } \\
Case & Import & Export & DoA & Grid & PV & CHP & BAT \\
\hline R & 71831.0 & 0.0 & 3.7 & 96.3 & 3.7 & 0.0 & 0.0 \\
NC & 839.27 & 13146.2 & 77.3 & 22.8 & 22.4 & 54.9 & 0.0 \\
PS & 401.5 & 12612.1 & 91.1 & 8.9 & 30.9 & 51.9 & 8.3 \\
\hline
\end{tabular}

In the PS case, when energy storage is added, and doublesided auction control is applied, the results, with respect to the NC case, are somewhat different. The yearly average electricity consumption is $4.5 \mathrm{MWh}$ per house, while the production per house is $16.7 \mathrm{MWh}$. The increase in both production and consumption per house is mainly attributed to the battery. Still, the majority of the electricity (12.9 MWh per house) is generated by the CHP as a by-product of the heat generation, however, only $2.3 \mathrm{MWh}$ of this is used locally. The PV-panels generate 3.8 MWh per house per year of which 1.4 MWh is used locally. Furthermore, the average yearly electricity import has decreased, by over $50 \%$, to $402 \mathrm{kWh}$ per house. The average yearly export per house is decreased 
slightly to $12.6 \mathrm{MWh}$. This yields a DoA of $91.1 \%$, which is clearly better than the NC case. Moreover, the battery usage is very limited, only $400 \mathrm{kWh}$ (or $8.3 \%$ ) of the total electricity demand is provided by the battery.

On the one hand, the existing neighbourhood performs much better in the PS case when compared to the NC case. More of the electricity generated by the PV-panels is used locally, and less electricity is imported from the grid. On the other hand, for both the NC and PS case, the largest part of the consumed electricity is provided by the CHP unit. This is due to the high thermal demand. To illustrate this, in Figure 6 the electricity production for the neighbourhood during the simulated year is shown, which shows the high electricity production during winter.

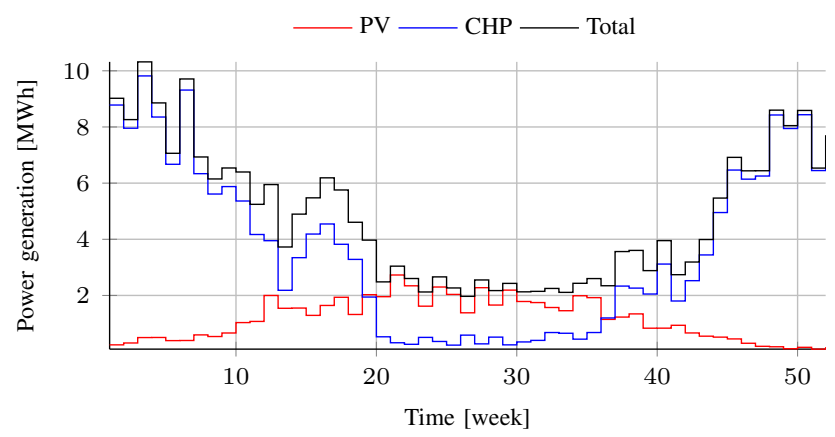

Fig. 6. Weekly electrical energy production of the CHP and all PV-panels combined, resulting from sizing choices.

Hence, a better improvement for this neighbourhood would be a reduction in its thermal demand through better insulation. Alternatively, one can conclude that the heat/electricity ratio of the CHP is far from optimal for this neighbourhood as discussed in [9].

\section{Conclusions}

In this work the practical applicability of the soft-islanding approach is explored, by applying this approach to an existing 16 house neighbourhood in Markluiden, the Netherlands. Based on the current physical characteristics of the 16 houses in the neighbourhood, the size of the CHP, PV-panels and battery is determined.

If the soft-islanding approach is applied together with storage and optimal control, a DoA of $91.1 \%$ is achieved. In this case, the electricity imported from the grid amounts to 402 $\mathrm{kWh} /$ year, the amount of electricity exported to the grid is even more substantial at $12.6 \mathrm{MWh} /$ year. This is a very different operation of the system compared to the present situation in Markluiden ( $R$ case), where almost the entire electricity load is imported from the grid, with a resulting DoA of $3.7 \%$. The large exports of electricity are clearly a consequence the large heat demand, which results in a CHP producing too much electricity while fulfilling the heat demand. Therefore, the part of the year where the electricity production is dominated by the PV-panels is only 16 weeks.
Therefore, we conclude that other steps are needed before installing a CHP, PV-panels and batteries. It would be prudent to use the steps of Trias Energetica [17] and start by applying it's first rule: "Limit energy usage by reducing losses". Hence the houses should be properly insulated before any renewable energy sources are added or soft-islanding solutions are applied.

\section{ACKNOWLEDGMENTS}

The authors thank the Dutch national programs TKI Switch2Smargrids (project Smart Grid Evolution) and TKI iDeego (project ORTEP) and the Dutch organization RVO for their support. Furthermore, the authors thank the residents of Markluiden for providing us the data that made this case study possible.

\section{REFERENCES}

[1] Ministerie van Economische Zaken, "Energieagenda - Naar een $\mathrm{CO}_{2}$ arme energievoorziening," 2016.

[2] ECN, Energie-Nederland, and Netbeheer Nederland, "Energietrends," 2016.

[3] Netbeheer Nederland, "Net voor de toekomst - Een vooruitblik op de energievoorziening in 2050," 2017.

[4] P. Siano, "Demand response and smart grids - A survey," Renewable and Sustainable Energy Reviews, vol. 30, pp. 461-478, 2014.

[5] R. H. Lasseter, "Smart Distribution: Coupled Microgrids," Proceedings of the IEEE, vol. 99, no. 6, pp. 1074-1082, 2011.

[6] P. Mancarella, "MES (multi-energy systems): An overview of concepts and evaluation models," Energy, vol. 65, no. C, pp. 1-17, 2014.

[7] S. Long, O. Marjanovic, and A. Parisio, "Demand smoothing in multienergy systems using model predictive control," in 2018 IEEE PES Innovative Smart Grid Technologies Conference Europe (ISGT-Europe), 2018, pp. 1-6.

[8] K. X. Perez, M. Baldea, and T. F. Edgar, "Integrated smart appliance scheduling and HVAC control for peak residential load management," in 2016 American Control Conference (ACC), 2016, pp. 1458-1463.

[9] K. X. Perez, M. Baldea, T. F. Edgar, G. Hoogsteen, R. P. van Leeuwen, T. van der Klauw, B. Homan, J. Fink, and G. J. M. Smit, "Soft-islanding a group of houses through scheduling of CHP, PV and storage," in 2016 IEEE International Energy Conference (ENERGYCON), Leuven, 2016, pp. 1-6.

[10] G. Hoogsteen, "A Cyber-Physical Systems Perspective on Decentralized Energy Management,” Ph.D. dissertation, University of Twente, 2017.

[11] M. E. T. Gerards, H. A. Toersche, G. Hoogsteen, T. van der Klauw, J. L. Hurink, and G. J. M. Smit, "Demand side management using profile steering," in PowerTech, 2015 IEEE Eindhoven, 2015, pp. 1-6.

[12] K. Kok, "The PowerMatcher: smart coordination for the smart electricity grid," Ph.D. dissertation, Vrije Universiteit Amsterdam, 2013.

[13] S. Nebiolo, "The potential for energy islands in the eastern Netherlands," Master's thesis, University of Twente, 2018.

[14] Agentschap NL, "Voorbeeldwoningen 2011: Onderzoeksverantwoording," 2011.

[15] G. Hoogsteen, A. Molderink, J. L. Hurink, and G. J. M. Smit, "Generation of flexible domestic load profiles to evaluate Demand Side Management approaches," in 2016 IEEE International Energy Conference (ENERGYCON), Leuven, 2016, pp. 1-6.

[16] KNMI, "Uurgegevens van het weer in Nederland," [Online] Available: http://www.knmi.nl, 2014, last accessed on 27-10-2017.

[17] R. van Leeuwen, "Towards $100 \%$ renewable energy supply for urban areas and the role of smart control," Ph.D. dissertation, University of Twente, 2017. 